DOI 10.37882/2223-2982.2020.12-2.31

\title{
ВЛИЯНИЕ ЭТНОКУЛЬТУРНЫХ ФАКТОРОВ НА РАЗВИТИЕ РЕЧИ У ДЕТЕЙ НАРОДОВ СЕВЕРА В ПРОЦЕССЕ ОБУЧЕНИЯ МАТЕМАТИКЕ
}

\section{INFLUENCE OF ETHNO-CULTURAL FACTORS ON THE DEVELOPMENT OF SPEECH IN CHILDREN OF THE PEOPLES OF THE NORTH IN THE PROCESS OF TEACHING MATHEMATICS}

\section{N. Spiridonova}

Summary: The school occupies a special place in rural society, as it is the cultural, social and economic center of the village. Within the walls of a rural school, the necessary organizational and pedagogical conditions are created that allow achieving educational and educational goals. In General education organizations located in places where indigenous peoples of the North live, it is important to take into account the level of language proficiency of schoolchildren, their ethnic culture and national mentality. This article discusses the ethno-cultural factors that influence the formation of mathematical speech in primary schoolchildren. Taking into account the identified factors, the features of the process of teaching the subject «Mathematics» in grades 5-9 are evaluated. Recommendations for teachers of mathematics are developed, which are recognized to promote the formation and development of mathematical speech in Russian.

Keywords: peoples of the North, state language, official language, ethnocultural factors, mathematical language, mathematical speech.
$\mathrm{H}$ а территории Российской Федерации русский язык носит статус государственного языка, является средством межнационального общения [7]. В Республике Саха (Якутия) принят второй государственный язык - язык саха. Эвенкийский, эвенский, юкагирский, долганский, чукотский языки признаются официальными языками в местах проживания этих народов и используются наравне с государственными языками [8]. Официальные языки республики изучаются в качестве учебного предмета в школах, в которых учатся дети коренной национальности. Изучение родного языка приобщает школьников к культуре, традициям своего народа, способствует сохранению языков коренных малочисленных народов Севера.

Язык представляет собой систему знаков, служащую средством человеческого общения, мышления и выражения [14 ]. А речь - это язык в действии [10], то есть
Спиридонова Наталья Ивановна

С.н.С., ФГБНУ «Научно-исследовательский Институт национальных школ Республики Саха (Якутия)» (2. Якутск),

tashachen@mail.ru

Аннотация: В сельском социуме школа занимает особое место, так как она является культурным, социальным и экономическим центром. В стенах сельской школы создаются необходимые организационно-педагогические условия, которые позволяют достигать образовательные и воспитательные цели. В общеобразовательных организациях, расположенных в местах проживания коренных малочисленных народов Севера, особенно важно учитывать уровень владения языками у школьников, их этнокультуру и национальную ментальность. В данной статье рассматриваются этнокультурные факторы, влияющие на формирование математической речи у обучающихся основной школы. С учетом выявленных факторов оценены особенности процесса обучения учебному предмету «Математика» в 5-9 классах. Разработаны рекомендации для учителей математики, признанные содействовать формированию и развитию математической речи на русском языке.

Ключевые слова: народы Севера, государственный язык, официальный язык, этнокультурные факторы, математический язык, математическая речь.

речь служит способом передачи мыслей с помощью языка [9]. В многоязычном обществе особую значимость имеет уровень владения устной и письменной речью на русском языке, так как он определяет качество коммуникативных и когнитивных процессов в различных сферах деятельности человека.

Математический язык является расширением естественного языка за счет символики и дополнительной лексики [5]. В узком смысле под математическим языком понимают систему математических символов [16], в широком смысле - систему, включающую средства родного языка, математическую терминологию, символику, графики, схемы и т.п. [13, с.11]. На уроках математики язык создает устную и письменную учебную среду [19]. Математическая речь позволяет школьникам применять математический язык для выражения своих мыслей. Система характеристик и качеств математической 
речи обеспечивает её коммуникативное совершенство [6]. Математическая речь подчиняется правилам естественного языка, но при этом язык обучения математике в школе отличается от языка изучаемой математической теории: не имеет столь высокой степени формализации, но превышает по степени формализации естественный язык. В процессе обучения математике элементы естественного языка играют большую роль, чем в языке математической науки [12]. Язык обучения математике представляет собой «систему, компонентами которой являются некоторая область естественного языка, дидактического языка и средства логико-математического языка, с помощью которых осуществляется обучение математике в школе» [15].

Так как математический язык является сложным специализированным языком [17], в процессе обучения математике многие школьники испытывают языковые затруднения [18]. Актуальность данной проблемы подтверждают работы многих ученых, в которых отмечается, что уровень развития речи современных школьников (в том числе математической речи) постепенно понижается [3]. Для обучающихся, владеющих более чем одним языком (билингвов, полилингвов), в том числе детей коренных малочисленных народов Севера, проблема формирования и развития математической речи требует особого внимания.

Теоретико-методологической основой данного исследования являются научные исследования в области этнолингвистики, которая представляет собой направление в языкознании, изучающее язык в его отношении к культуре, взаимодействии языковых, этнокультурных и этнопсихологических факторов в функционировании и эволюции языка [1]. По мнению А.С. Герда предметом изучения этнолингвистики является «язык в его соотношении с этносом, место и роль языка в обществе» [4]. Применение этнолингвистического подхода можно увидеть в работах И.Г. Гердера, В. Гумбольдта, Ф. Боаса, Э. Сепира, Ж. Фрибур, М.И. Исаева, С.И. Брука, М.Н. Губогло, Э.Ю. Венецкая, В.А. Ачкасова, С.А. Бондаренко, О.М. Сичинава и т.д.

В рамках нашего исследования для нас представляет интерес понятие «этнолингвистический фактор». Разные авторы данный термин заменяют такими понятиями, как «язык в полиэтническом пространстве», «этнолингвистические процессы» (М.И. Исаев, С.И. Брук, М.Н. Губогло), «этнолингвистические проблемы» (Э.Ю. Венецкая), «этнолингвистическая мобилизация» (М.Н. Губогло, В.А. Ачкасов).

По мнению С.А. Бондаренко [2] этнолингвистический фактор связан с многовековыми традициями, многонациональным этническим составом стран, стремлением каждого народа сохранить свой язык и культуру. В связи с этим этнолингвистический фактор является препятствием на пути интеграционных процессов в сфере образования.

Мы будем опираться на определение О.М. Сичинава, который под этнолингвистическим фактором понимает «совокупность определенных условий взаимодействия языка, культуры и национальной ментальности, при которых достигается структурное единство данных компонентов, направленное на гармоничное развитие общества» [11]. Понятие «этнолингвистический фактор» мы будем рассматривать как совокупность условий взаимодействия языка, этнокультуры, национальной ментальности, направленных на сбалансированное развитие математической речи обучающихся сельских школ.

Данное исследование было проведено с целью выявления этнокультурных факторов, влияющих на формирование письменной и устной математической речи на русском языке у обучающихся 5-9 классов сельских образовательных организаций, расположенных в местах проживания коренных малочисленных народов Севера Республики Саха (Якутия).

В ходе исследования был применен эмпирический метод - анкетирование. Всего в исследовании принимали участие 44 респондента, из них - 27 обучающихся 5-9 классов, 8 учителей математики и 9 родителей из 4 общеобразовательных организаций Олекминского, Кобяйского, Нижнеколымского, Анабарского районов Республики Саха (Якутия).

Для отбора респондентов мы ориентировались на изучение языков коренных малочисленных народов Севера в школе: эвенский, эвенкийский, долганский, чукотский.

Был определен национальный состав респондентов и их родной язык: 9 обучающихся считают себя чукчами, 7 - эвены, 5 - долганы, 4 - эвенки. 2 школьника в графе национальности указали несколько вариантов одновременно, например, чукча, русский и саха; эвенк и саха. 6 обучающихся родным языком считают язык саха, 7 эвенский язык, 5 - чукотский язык, 4 - русский язык, 2 эвенкийский язык, 1 - долганский язык, 1 - эвенкийский язык и язык саха, 1 - эвенский язык и язык саха.

5 родителей - эвены, 1 родитель - саха, 3 родителя - долганы. У 5 из них родной язык - эвенский язык, у 3 родителей - язык саха, 1 родитель в качестве родного языка указал сразу язык саха и долганский язык.

Из ответов обучающихся мы поняли, что 93\% из них являются членами полных семей, из которых $30 \%$ - полилингвальные семьи. У $37,5 \%$ детей национальность совпадает с национальностью матери, у стольких же - 
отца. 25\% считают, что их национальность, отличается от национальности родителей, например, ребенок - эвенк, мать - саха, отец - русский.

Стоит также отметить, что половина учителей идентифицировали себя с представителями народа саха, 2 учителя - эвенки, 1 учитель - эвен, 1 учитель - долган. У $87,5 \%$ учителей родной язык соответствует их национальности, кроме 1 учителя, который является представителем народа саха, но родным языком считает русский язык.

Относительно уровня владения родным языком обучающимися и их родителями мы получили следующие сведения (таблица 1).

Таблица 1.

Уровень владения родным языком.

\begin{tabular}{|l|c|c|c|}
\multicolumn{1}{r|}{ Уровень владения } & обучающиеся & Родители & Учителя \\
\hline Свободно владеют. & $12,50 \%$ & $12,50 \%$ & $37,50 \%$ \\
\hline Понимают и говорят. & $12,50 \%$ & $12,50 \%$ & $37,50 \%$ \\
\hline Понимают, но не говорят. & $37,50 \%$ & $25 \%$ & $25 \%$ \\
\hline Не владеют. & $12,50 \%$ & $12,50 \%$ & $0 \%$ \\
\hline Затруднились ответить. & $25 \%$ & $37,50 \%$ & $0 \%$ \\
\hline
\end{tabular}

Уровень владения русским языком у обучающихся и их родителей отобразим в таблице 2.

Таблица 2.

Уровень владения русским языком.

\begin{tabular}{|l|c|c|}
\hline \multicolumn{1}{|c|}{ Уровень владения } & Ученик & Родитель \\
\hline Высокий & $22 \%$ & $40 \%$ \\
\hline Выше среднего & $19 \%$ & $30 \%$ \\
\hline Средний & $49 \%$ & $26 \%$ \\
\hline Ниже среднего & $10 \%$ & $4 \%$ \\
\hline Низкий & $0 \%$ & $0 \%$ \\
\hline
\end{tabular}

Половина учителей считает, что уровень владения родным языком влияет на успехи школьников в изучении математики на русском языке. $25 \%$ учителей, наоборот, указали, что не влияет, оставшиеся 25\% не смогли ответить на данный вопрос.

Большая часть детей (58\%) думают, что знание родного языка не влияет на то, как они выражают свои мысли на русском языке при обучении математике, 34\% отвечают, что им родной язык помогает, $4 \%$ - мешает, $4 \%$ - затруднились ответить.

Мнения родителей о влиянии владения родным языком обучающимися на развитие их речи на русском языке разделились: 44,4\% родителей говорят, что влияет положительно, 44,4\% - не влияет, $11,2 \%$ - не ответили.
Уровень развития устной и письменной математической речи обучающихся учителя оценивают следующим образом: 75\% учителей считают, что устная математическая речь сформирована на среднем уровне, 25\% низком. По мнению $62,5 \%$ учителей письменная речь школьников имеет средний уровень, 37,5\% - низкий.

Устную и письменную математическую речь обучающихся 5-9 классов учителя характеризуют следующими коммуникативными качествами: правильная, точная, логичная, выразительная, богатая, чистая. По мнению учителей письменная математическая речь более точная и правильная, чем устная. Кроме того, только письменную речь учителя характеризуют как чистую, только устную речь как богатую. Устная речь в два раза логичнее, чем письменная. Обе формы речи выразительны в одинаковой степеней.

На уроках математики (или во внеурочной деятельности) в качестве языка обучения половина учителей использует только русский язык; 37,5\% - язык саха и русский язык, но больше русский язык; 12,5\% - родной и русский языки, но больше русский язык.

В ходе анкетирования мы также установили, что больше половины учителей и обучающихся смешивают языки обучения математике (в рамках одного предложения, абзаца, текста).

Многие школьники считают, что использование понятий из окружающего мира (история, обычаи, традиции твоего народа, выдающиеся личности твоего села, названия озер, рек и др.) помогает выражать мысли на русском языке при обучении математике.

О положительном влиянии использования региональных, исторических и этнокультурных материалов на речемыслительную деятельность на русском языке указали 74\% обучающиеся, 12\% считают, что влияние является негативным, 14\% - нейтральным.

Также 66,7\% родителей считают, что на развитие речи на русском языке положительно влияет использование таких материалов, 22,2\% указали, что никакого влияния нет, $11,1 \%$ - не ответили.

Оказалось, что 75\% учителей иногда используют этнокультурные, исторические, краеведческие материалы при обучении математике в основном при решении текстовых задач, остальные $25 \%$ - не используют. При этом во внеурочной деятельности подобные материалы учителя используют чаще.

Мнение учителей по поводу необходимости для школ коренных малочисленных народов Севера специально разработанных учебных пособий по математике, 
учитывающих языковые, этнокультурные особенности обучающихся распределились следующим образом: 50\% учителей думают, что такие пособия нужны, 37,5\% не видят в них необходимости, 12,5\% затруднились высказать свое мнение по этому поводу.

Итак, результаты анкетирования среди обучающихся 5-9 классов, их родителей и учителей математики дают нам возможность сделать следующие выводы:

- В сельской местности Республики Саха (Якутия), где проживают представители коренных малочисленных народов Севера, сформировна полилингвальная учебная среда на родном, якутском и русском языках.

- Родной язык некоторых обучающихся отличается от языка этнической принадлежности. Некоторые дети указывают несколько языков в качестве родного языка.

- Государственные языки имеют огромное влияние: $22 \%$ школьников считает своим родным языком язык саха, $15 \%$ - русский язык.

- Большая часть респондентов владеют родным языком в разной степени (свободно владеют; понимают речь других людей, могут говорить; понимают, но не говорят).

- Количество детей, у которых высокий (или выше среднего) уровень владения русским языком, преобладает среди детей, не владеющих родным языком. Уровень владения русским языком обучающимися, которые свободно владеют родным языком, находится на среднем уровне.

- Многие респонденты (обучающиеся, родители, учителя) отмечают пользу владения родным языком на развитие речи на русском языке.

- Половина учителей, участвовавших в анкетировании, являются представителями народа саха.

- Русский, родной и якутский языки используются в качестве языка обучения на уроках математики или во внеурочной деятельности. При этом учителя и обучающиеся смешивают языки обучения.

- Многие респонденты указали, что использование исторических, этнокультурных и региональных материалов при обучении математике помогает школьникам строить осмысленные высказывания на русском языке.
Таким образом, результаты проведенного исследования стали основой для разработки рекомендаций, которые будут направлены на повышение эффективности педагогической деятельности по формированию и развитию письменной и устной речи на русском языке у школьников при обучении математике в 5-9 классах сельских образовательных организаций, расположенных в местах проживания коренных малочисленных народов Севера. Таким образом, учителям математики рекомендуем комплекс мер, учитывающий особенности этнолингвистических факторов:

- мотивировать обучающихся к достижению не только предметных, но и языковых целей;

- учитывать уровень владения языками (родным, русским, якутским);

- требовать, чтобы ученики осознанно воспроизводили речевые действия, осознавали и точно отражали языковые явления, структуры и термины;

- целенаправленно оказывать языковую поддержку (при необходимости использовать родной язык обучающихся, а также язык саха; научить осознанно переключаться с одного языка на другой (не смешивать языки));

- применять приемы и методы билингвального обучения;

- использовать задания, которые составлены с учетом этнокультурных и языковых особенностей обучающихся, направлены на развитие устной и письменной математической речи (исторические, этнокультурные и краеведческие материалы; комплекс упражнений для развития коммуникативных качеств математической речи).

Проведенное исследование показало, что в условиях полилингвального образования существенна роль этнолингвистических факторов, влияющих на формирование и развитие устной и письменной математической речи на русском языке. Применение на уроках математики или во внеурочной деятельности разработанных рекомендаций будет способствовать не только развитию математической речи, но и речи в целом, а также качественному усвоению программы основной школы обучающимися сельских общеобразовательных школ, расположенных в местах проживания коренных малочисленных народов Севера.

\section{ЛИТЕРАТУРА}

1. Большая Российская энциклопедия: в 30 т. / научно-редакционный совет: председатель - Ю.С. Осипов и др. - М., 2004, 30 т.

2. Бондаренко С.А. Этнолингвистические проблемы формирования общего образовательного пространства Европейского Союза: дисс. канд. пед. наук: 13.00.01 / Бондаренко Сергей Александрович. - Рязань, 2009. - 206 с.

3. Великанов Ю.Б. Развитие речи учащихся на уроках математики / Ю.Б. Великанов // Методологические знания как основа развивающего обучения математике. - Н. Новгород, - 1995. - С. 81-90.

4. Герд А.С. Введение в этнолингвистику»: курс лекций и хрестоматия. 2-е изд., исправл. - СПб.: Изд-во С.-Петерб. ун-та, 2005. - 457 с. 
5. Дорофеев Г.В. 0 некоторых особенностях реального языка математики // Математика в школе. - 1999. - №6. - С. 41-43.

6. Иванова Т.А., Горчаков А.С. Развитие математической речи школьников в процессе изучения определения понятий, теорем, правил // Современные проблемы науки и образования. - 2013. - № 6. [Электронный ресурс]. URL: http://www.science-education.ru/ru/article/viewid=10814 (дата обращения: 20.09.2020).

7. Конституция Российской Федерации. [Электронный ресурс]: принята всенародным голосованием 12.12.1993 (с изменениями, одобренными в ходе общероссийского голосования 01.07.2020). // СПС «Консультант плюс». - Режим доступа: http://www.consultant.ru/document/cons_doc_LAW_28399/.

8. 0 языках в Республике Саха (Якутия): Закон Республики Саха (Якутия) от 16.10.1992 № 1170-ХІІ (с изм. и доп.). Доступ из справ. правовой системы «Гарант». Источник: https://base.garant.ru/26701253/

9. Ожегов С.И. Словарь русского языка: Ок. 53000 слов / Под общ. ред. проф. Л.И. Скворцова. - 24-е изд., испр. - М.: Оникс, Мир и 0бразование, 2007. $1200 \mathrm{c}$.

10. Рубинштейн С.Л. Основы общей психологии. - СПб.: Питер, 2000. - 712 с.

11. Сичинава 0.М. Этнолингвистический фактор: основные терминологические и структуральные параметры. Вопросы теории и практики, Тамбов, 2017, $187-188 \mathrm{c}$.

12. Столяр А.А. Логические проблемы преподавания математики. Минск: Высшая школа, 1965. - 254 с.

13. Тесленко И.Ф. Научно-техническая революция и математика в школе. - Киев: Знание, 1973. - 31 с., с.11.

14. Философский энциклопедический словарь. - М.: Советская энциклопедия. Гл. редакция: Л.Ф. Ильичёв, П.Н. Федосеев, С.М. Ковалёв, В.Г. Панов. 1983.

15. Шармин Д.В. Формирование культуры математической речи учащихся в процессе обучения алгебре и началам анализа: Дис. ... канд. пед. наук. - Омск, 2005. -209 c.

16. Шиханович Ю.А. введение в современную математику. Начальные понятия. - М.: Наука, 1965. - 376 с.

17. Gabler L., \& Ufer S. (n.d.). Sprachliche Flexibilität von Grundvorstellungen zu Addition und Subtraktion - Eine Vorstudie zu einem Förderkonzept für die zweite Jahrgangsstufe. Journal für Mathematikdidaktik, under revision.

18. Maier H., \& Schweiger F. (1999). Mathematik und Sprache: Zum Verstehen und Verwenden von Fachsprache im Mathematikunterricht. Wien: oebv + hpt.

19. Pimm D. (1987). Speaking mathematically: Communication in mathematics classrooms. Language, education, and society. London: Routledge.

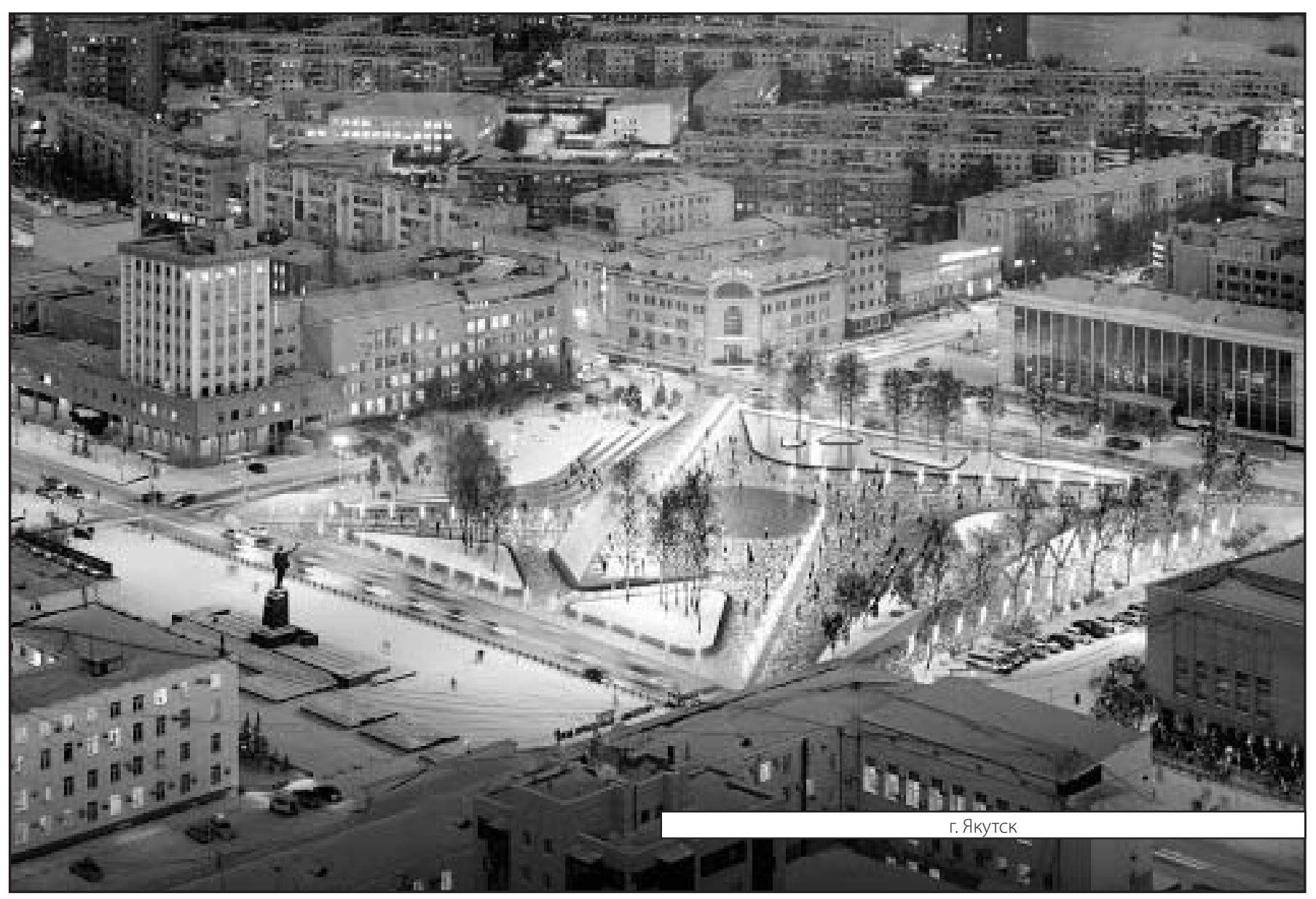

